\title{
A supervisão de estágio como analisador da articulação interorganizacional Escola de Enfermagem e Hospital
}

\author{
Ana Paula Macedo \\ Universidade do Minho, Portugal
}

Resumo

Este estudo, que reflecte sobre a supervisão de estágios, não constitui uma questão nova no âmbito da Enfermagem. No entanto, a questão como objecto de investigação organizacional aparece no contexto português com alguma novidade. O texto debruça-se sobre as orientações e as práticas de supervisão de estágios em Enfermagem como analisador dos fenómenos de articulação interorganizacional Escola de Enfermagem e Hospital. O percurso desta investigação foi de entrelace entre algumas mudanças na supervisão de estágios e algumas mudanças sociais e políticas das organizações em estudo - Escola de Enfermagem e Hospital -, estabelecendo-se relações sociologicamente pertinentes entre ambas. $O$ valor heurístico deste percurso propiciou a (re)construção de um modelo teórico de análise da articulação interorganizacional Escola de Enfermagem e Hospital, onde se elegeram duas vertentes de análise para a sua compreensão. Será aqui apresentado o ensaio teórico-metodológico deste estudo de caso, que nos permitiu realizar a leitura dos discursos e das práticas em contexto de supervisão de estágio, no Plano da Acção/Sistema da Acção.

Palavras-chave

Supervisão de estágios; Articulação Escola de Enfermagem e Hospital; Configurações de articulação

O exercício de articulação entre a Escola de Enfermagem e o Hospital exige uma reflexão da nossa parte, estimulada pelo estudo da supervisão de 
estágios, permitindo-nos esboçar, dentro de certos limites, algumas semelhanças e diferenças entre as duas organizações. Uma análise a priori das duas organizações parece apontar para uma evidência espontânea que as reaproxima em dois domínios: o dos cuidados e o da educação ${ }^{1}$. Assim, a confrontação tem como objectivo identificar as articulações que temos colocado em questão desde as suas origens. As perguntas orientadoras são as seguintes:

- Será que a articulação entre Escola de Enfermagem e Hospital, ao ser reveladora das semelhanças/diferenças entre as duas organizações, favorece a supervisão de estágios?

- Será que a articulação entre Escola de Enfermagem e Hospital favorece a integração dos alunos estagiários de Enfermagem no contexto de trabalho hospitalar?

O interesse em comparar a Escola de Enfermagem e o Hospital inscreve-se, na actualidade, num quadro mais vasto, que é o da caracterização da modernização-racionalização das actividades dos serviços. Nestas duas organizações, pressente-se um processo de modernizaçãoracionalização das actividades e, igualmente, transformações das actividades, que afectam os agentes beneficiários (alunos e doentes) e os prestadores de cuidados (professores e enfermeiros) - prestadores estes que, para a maioria, exercem uma profissão que pode ser chamada, ao mesmo tempo, de relacional e de semi-especialistas menos típicos ${ }^{2}$ (Etzioni, 1984: 119), caracterizada pelo status intermediário na sociedade e no lugar das políticas públicas. Por isso é que o conjunto dos serviços constituirá o objectivo pertinente, interessante e original de comparar as transformações da Escola de Enfermagem e destas Escolas ao sector privado de domínio empresarial, por exemplo ${ }^{3}$.

A noção de relação, presente em algumas análises produzidas pela Sociologia, pela Economia e pela Gestão, pode ser definida como uma interacção entre o prestador e um beneficiário, satisfazendo certas necessidades do beneficiário (em vez de uma mera prestação de serviços) ${ }^{4}$. Sendo assim, a crítica que emerge à hipótese lançada de comparar a Escola (de Enfermagem) a um conjunto de serviços é que não é possível diferenciálos claramente. As evoluções tendenciais (aumento da produtividade, individualização das prestações de cuidados, desenvolvimento da avaliação) 
não separam na totalidade o universo industrial do universo terciário. Neste caso, é importante distinguirmos uma racionalização industrial, própria da produção de bens, de uma racionalidade profissional, própria dos serviços.

Para Demailly \& Dembinski (2002), cujas temáticas de estudo têm incidido nos modos de regulação e transformação dos sistemas de saúde, políticas públicas e grupos profissionais, há interesse em mostrar o carácter profundamente conflitual da noção de racionalidade económica. Os conflitos internos da racionalidade económica, como da racionalidade organizacional, estão presentes em vários sectores. A racionalização colocada em prática no universo industrial e terciário parece apresentar um fenómeno similar: a mesma tensão, a mesma coexistência contraditória entre as mudanças organizacionais neo-taylorianas e as mudanças de um outro tipo, "fordistas" ou participativas. Notam ainda Demailly \& Dembinski (2002) que o lugar do neo-taylorismo - a racionalização dos fluxos (de papéis, de decisões, de informações, etc.), a centralização da informação nos poderosos sistemas informatizados, a intensificação do trabalho, a estandardização contínua dos procedimentos, os esforços da avaliação, as performances de cada um - faz emergir novos tipos de experts e de cronómetros para medir o trabalho ${ }^{5}$.

Como destacam Demailly \& Dembinski (2002: 45), a ideia de uma modernização-racionalização, funcionalmente contraditória, que concerne todas as organizações produtivas, industriais ou serviços comerciais e não comerciais, oferece bens ou prestações, materiais ou relacionais, operando sobre os bens da pessoa ou da pessoa a si própria, a partir de uma base empírica verificável. Se, por um lado, há uma aproximação da indústria aos serviços - nomeadamente através da importância da figura do cliente como membro à parte de uma organização produtiva, da importância da gestão e do espírito gestionário ou do empreendedorismo, do desenvolvimento da produção sobre a medida, da venda de serviços presos aos produtos e os produtos aos serviços, das relações entre clientes e fornecedores internos por outro, as actividades de serviço aproximam-se da indústria: procura de economias de escala (tradicionalmente "inventadas" na indústria), compressão do "trabalho vivo" ao proveito das máquinas, organização de intensificação do trabalho.

É neste enquadramento que situamos as actuais políticas públicas de modernização e de reforma, que integram frequentemente pressupostos, 
adoptam orientações e consagram soluções híbridas de tipo neo-tayloriano e de tipo "fordista" ou participativo (Messine, 1991; Lima, 1994). Foi tomando como enfoque estas soluções híbridas que procurámos analisar algumas dimensões organizacionais presentes na Escola de Enfermagem e no Hospital, em contexto de supervisão de estágios, procurando as articulações possíveis.

\section{Configurações da articulação Escola de Enfermagem e Hospital em contexto de supervisão de estágio no plano das Orientações para a Acção Organizacional/Sistema de Pensamento e Ideias}

Se, numa primeira fase deste estudo, a tipologia das organizações educativas de Per-Erik Ellström (1983) - considerando os Modelos RacionalBurocrático, de Sistema Social, Político e Anárquico - oferece um conjunto de alternativas que, combinadas, podem ajudar-nos a construir uma visão plural da supervisão de estágios na articulação Escola de Enfermagem e Hospital, numa segunda fase, esta tipologia continuará a ser-nos útil para uma melhor focalização e compreensão do nosso objecto de trabalho.

É, seguramente, um dos objectivos primordiais que enforma o estudo desvendar globalmente o significado da relação interorganizacional Escola de Enfermagem e Hospital e, especificamente, a desocultação do conjunto de concepções e procedimentos que giram em torno da questão da supervisão de estágios.

De acordo com a proposta de modelo teórico para a compreensão da supervisão de estágios em contexto de trabalho hospitalar, traçada no nosso trabalho de investigação, o estudo no domínio da articulação interorganizacional Escola de Enfermagem e Hospital é agora realizado sob influência da proposta de William Tyler (1991: 31), que serviu de base para o ensaio do nosso exercício. Nesta perspectiva, elaboramos uma tipologia para a interpretação da articulação organizacional - que apelidamos de Configurações da articulação Escola de Enfermagem e Hospital - tendo utilizado os dois planos analíticos de Licínio Lima (1998: 581-601; 2003: 105111) - o Plano das Orientações para a Acção e o Plano da Acção Organizacional -, em combinação com os dois sistemas diferentes dentro das 
organizações de Nils Brunsson (2006: 200) - o Sistema de Pensamento e Ideias e o Sistema de Acção. Embora os planos e os sistemas sejam distintos nas suas definições, há analogias que podem ser estabelecidas, na medida em que ambos estão dependentes de dois tipos de interpretação: uma ao nível do que deve ser, ou do que se pensa que deve ser, e outra ao nível daquilo que é.

No primeiro Plano analítico das Orientações para a Acção e de Sistema de Pensamento e Ideias, integramos elementos contextuais que, ao serem confrontados com os cenários passíveis de serem observados no domínio da empiria, nos permitem esboçar a seguinte tipologia de configurações de articulação Escola de Enfermagem e Hospital, em contexto de supervisão de estágio, com a possibilidade de ser associada à tipologia organizacional de Ellström (1983): Articulação Eficiente - Imposta; Articulação de Interdependência e Colaboração - Integrativa/Adaptativa; Articulação Conflitual - Estratégica; Articulação Débil - Simbólica. Passemos à descrição muito breve de cada uma das categorias contempladas na tipologia das respostas organizacionais.

\section{Articulação Eficiente - Imposta}

Trata-se de uma configuração que conduz a uma concepção de articulação interorganizacional entendida como uma tecnologia racional para a tomada de decisões. A articulação vincula-se a partir do momento em que são definidas as estruturas adequadas para assumir as funções administrativas e poder tomar decisões, com base em objectivos definidos a priori. As organizações que se articulam orientam-se por normativos claros e documentos que esclarecem com rigor as sequências de um programa de acção e os modos de funcionamento e de comportamento dos actores, bem como os resultados esperados. A articulação eficiente é uma articulação imposta, no sentido de um imperativo de natureza técnico-racional, tendo por base um objectivo comum que é assegurar o correcto funcionamento dos serviços. 


\section{Articulação de Interdependência e Colaboração - Integrativa/Adaptativa}

A concepção de articulação de interdependência e colaboração afastase da configuração de articulação eficiente, anteriormente descrita, já que a dimensão formal, racional e estrutural desta, presente na planificação de um programa, é agora substituída por uma contextura informal dirigida à valorização individual e grupal dos membros de cada uma das organizações. A relação interorganizacional forte é um dos grandes objectivos, por isso investe-se em programas, processos de integração e adaptação, de interdependência e de colaboração, garantindo, desta forma, a confiança e a satisfação dos vários elementos. Neste tipo de articulação, são tidas em conta as tradições, os valores, as normas, os princípios organizativos, as relações hierárquicas, as relações entre pares, a comunicação dentro de cada serviço e entre diferentes serviços, a importância que se atribui ao trabalho e à produção. O que se designa por "cultura organizacional" agrupa um conjunto de condições que tornam a articulação fortemente socializadora e produtora de identidades profissionais.

\section{Articulação Conflitual - Estratégica}

A configuração de articulação conflitual realça a luta de interesses que os vários grupos desencadeiam entre si em ordem à obtenção dos seus objectivos sectoriais, socorrendo-se, para isso, de diversidades estratégicas de influência e de mecanismos de afirmação do seu poder em função de processos negociais, donde surgem vitoriosos os grupos ou as coligações dominantes. A actividade política é uma dimensão essencial na articulação entre as organizações; como tal, o conflito não é representado necessariamente como um problema. Os recursos muitas vezes são insuficientes, ou mal distribuídos, e as pessoas agem consoante os seus interesses, impondo algumas estratégias em termos de mobilização de recursos e de vontades convocadas. $\mathrm{Na}$ abordagem política, mais importante do que a regulação dos conflitos, são as estratégias e as tácticas do confronto.

\section{Articulação Débil - Simbólica}

A articulação interorganizacional é simbólica, frouxa ou "loosely coupled" (Weick, 1976: 3). As estruturas e os órgãos de cada uma das 
organizações não têm uma união forte, uma coordenação eficiente e racional. O investimento participativo dos gestores dessas estruturas é débil, eles podem criar momentos formais sem grande intenção de que os seus efeitos interfiram na acção real. Os acontecimentos interorganizacionais surgem relativamente desconectados, embora muitas vezes publicitados como sendo pensados em conjunto. Os acordos estabelecidos entre as partes das organizações raras vezes são postos em prática. Mesmos os dispositivos de controlo, quando existem, servem para legitimar a articulação interorganizacional e a sua estabilidade, mais do que os seus efectivos funcionamentos. Neste tipo de articulação, o simbolismo assume uma importante questão para manter "a união do sistema".

Assim, as categorias enunciadas foram ajustadas aos dois eixos conceptuais deste nosso ensaio teórico-metodológico, também apresentados por William Tyler (1991: 31). No primeiro eixo, o enfoque estruturalista e/ou a Teoria da Organização Formal. No segundo eixo, o enfoque interpretativo e/ou o Modelo de Ajuste Articulado de Modo Impreciso ou Sistema Debilmente Articulado (Weick, 1976). Se o primeiro caso nos remete para um tipo ideal de "Organização Acção", o segundo caso, para um tipo ideal de "Organização Política" (Brunsson, 2006).

A conceptualização de Brunsson, de dois tipos ideais distintos mas complementares em termos analíticos, de funcionamento das organizações, bem como de modos também distintos de as descrever - "a Organização Acção" e "a Organização Política" - constitui um recurso com potencialidades heurísticas para a abordagem que pretendemos tecer sobre a supervisão de estágios em Enfermagem e a relação interorganizacional Escola e Hospital.

O primeiro tipo ideal de "Organização Acção" assume posições teóricas com características burocrático-racionais e de sistema social, cujo princípio de recrutamento e de trabalho é o acordo e a hierarquia (Brunsson, 2006: 37). Na organização para a acção, são formuladas regras concretas e firmes para os comportamentos dos seus membros. As ideias e os valores predominantes acerca dessa mesma organização, bem como do seu ambiente, são partilhados por todos os membros. Neste sentido, uma "poderosa" ideologia não necessita de uma tomada de decisões, pelo que todo o processo é irracional. Uma outra característica é que a organização para a acção é sobretudo direccionada para soluções, e não para problemas 
- daí a abolição de todo o tipo de conflito, pretendendo-se, antes de mais, o consenso partilhado e o cultivo de uma enorme confiança entre os membros da organização.

\section{Quadro 1 - Representação de um arquétipo de configurações da articulação Escola de Enfermagem e Hospital, em contexto de supervisão de estágio, no Plano das Orientações para a Acção \\ Organizacional (Lima, 1998, 2003)/Sistema de Pensamento e Ideias} (Brunsson, 2006)

\begin{tabular}{|c|}
\hline Enfoque Estruturalista/ Teoria da Organização Formal (William Tyler, 1991: 31) \\
\hline Tïpo Ideal - "Organização Acção" (Brunsson, 2006) \\
\hline Modelo racional-burocrático (Ellström, 1983) \\
\hline Articulação Eficiente - \\
\hline$\{$ Imposta \\
\hline Modelo de sistema social (Ellström, 1983) \\
\hline Articulação de Interdependência e Colaboração - \\
\hline$\{$ Integrativa/Adaptativa \\
\hline $\begin{array}{l}\text { Enfoque Interpretativo/ Modelo de Ajuste Articulado de Modo Impreciso (William Tyler, 1991: 31) ou } \\
\text { Sistema Debilmente Articulado (Karl Weick, 1976) }\end{array}$ \\
\hline Tîpo Ideal - "Organizaçấo Politica" (Brunsson, 2006) \\
\hline Modelo político (Ellström, 1983) \\
\hline Articulação Conflitual \\
\hline$\{$ Estratégica \\
\hline Modelo anárquico (Ellströn, 1983) \\
\hline Articulação Débil \\
\hline \{Simbólica \\
\hline
\end{tabular}

Relativamente ao segundo tipo ideal, a "Organização Política" remetenos para uma outra face da organização cuja base de legitimidade é a reflexão de normas inconsistentes. As estruturas e os processos estão, assim, orientados para o ambiente. As concepções teóricas nas quais os seus 
argumentos se baseiam são não convencionais e realçam as dimensões ambíguas e certas dimensões políticas das organizações. Quase sempre estão presentes várias ideologias para discussão, capazes de promoverem a crítica e o conflito. Ao contrário do primeiro tipo ideal, a tomada de decisões é racional. Por seu lado, a hipocrisia é um comportamento fundamental na organização política.

Neste sentido, esta perspectiva (neo)institucional permite-nos uma interpretação crítica da articulação interorganizacional Escola de Enfermagem e Hospital, que passaremos de imediato a descrever tendo em conta os três factores de Brunsson (2006: 199): as ideias (identificação do que é tratado nos processos mentais e comunicativos, expressas através do discurso, tendo por alvo outros membros organizacionais ou ouvintes externos), as decisões (identificação do mecanismo de ligação entre as ideias e as acções), e as acções (descrição das fontes imediatas dos produtos da articulação).

A leitura dos dados recolhidos (através de inquérito por entrevista, de grelhas de observação e de reflexões de estágio) aos actores em contexto de supervisão de estágio, num serviço de Medicina, é realizada a partir de uma grelha de análise que emergiu do quadro conceptual do estudo. A partir deste momento, lançamos à prova outras configurações de articulação Escola de Enfermagem e Hospital, em contexto de supervisão de estágio, que não resultaram exclusivamente de um processo de dedução teórica (isto é, decorrentes dos modelos e teorias que conceptualmente as suportam), mas sim de uma articulação que se foi desenvolvendo entre a conceptualização teórica e os dados da investigação empírica - os quais foram esclarecendo, completando e legitimando os pressupostos teóricos que conduziram a nossa presença no contexto hospitalar. A metodologia de suporte ao estudo da articulação Escola de Enfermagem e Hospital, em contexto de supervisão de estágio, enquanto objecto de investigação empírica, aproxima-se da investigação de tipo etnográfico ou, para sermos mais sistemáticos, de um paradigma de investigação naturalista, cujo método é o estudo de caso. $O$ período em que mantivemos presença assídua no contexto de estágio ocorreu nos meses de Janeiro e Fevereiro de 2007. 


\subsection{A articulação Escola de Enfermagem e Hospital num tipo de "Organização Acção" - Entre as ideias, decisões e acções}

Tendo por base os pressupostos teóricos do Modelo RacionalBurocrático e do Modelo de Sistema Social (Ellström, 1983), remetemos as respectivas configurações de articulação Escola de Enfermagem e Hospital, em contexto de supervisão de estágio, para a Articulação Eficiente - Imposta e a Articulação de Interdependência e Colaboração - Integrativa/Adaptativa, como sendo as possibilidades presentes nestes dois modelos. Pretende-se caracterizar um conceito de supervisão de estágios na articulação interorganizacional Escola de Enfermagem e Hospital enquanto dispositivo normativo de formalização dos objectivos das duas organizações, em ordem à racionalização da acção interorganizacional.

Parte-se, portanto, do princípio que as organizações dispõem de objectivos próprios que orientam a sua acção - objectivos formais e oficiais e que, para atingir determinados resultados, se torna imprescindível definir previamente onde (e de que forma) se pretende chegar, podendo então o Protocolo de Articulação Institucional entre a Escola de Enfermagem e o Hospital ser entendido como o lugar privilegiado para a indicação clara das intenções das duas organizações.

A iniciativa do cumprimento do Protocolo de Articulação Institucional entre a Escola de Enfermagem e o Hospital parte das duas administrações, onde são tornados explícitos os objectivos e sua extensão e fixados os contributos ou serviços de cada organização na obra comum. Nesta missão, é necessário que nada seja fonte de conflito ou "entre em choque com os princípios e as regras de uma boa administração", mas sim que as acções adoptadas sejam facilitadoras da aplicação desses princípios e regras, para que a estabilidade do funcionamento organizacional seja possível. É, portanto, em nome do funcionamento racional, lógico e eficiente das organizações Escola de Enfermagem e Hospital, designadamente prestando atenção a uma correcta e planificada gestão de recursos, humanos, materiais e financeiros, que se justifica o esforço dispendido na construção de documentos formais, como o protocolo que articula institucionalmente a Escola Superior de Enfermagem com o Hospital - protocolo que se rege pelo Decreto-Lei $n^{\circ} 99 / 2001$, de 28 de Março, pelo Despacho do Gabinete do Ministro da Saúde $\mathrm{n}^{\circ} 15626 / 2004$ ( $2^{\mathrm{a}}$ série), de 4 de Agosto, e pelas 
disposições aplicáveis a tudo o que não estiver previsto nestes diplomas, pelas cláusulas indicadas nesse mesmo documento.

A Comissão Mista Permanente (constituída pelo Presidente do Conselho de Administração do HSM, ou um seu delegado; o Presidente da ESE-CG, ou um seu delegado; o Director do Curso da ESE-CG, ou um docente por si indicado; o Enfermeiro Director do HSM, ou um seu adjunto; o vogal não executivo previsto no $n^{\circ} 2$ do art. ${ }^{\circ} 7^{\circ}$ do D.L. $n^{\circ} 206 / 2004$, de 19 de Agosto, quando exista), tem competência para

(...) a) deliberar sobre as matérias relativas ao Regime de Articulação; b) definir a correspondência entre os estágios a realizar no HSM e os departamentos ou serviços hospitalares existentes ou a criar onde deverão decorrer os estágios; c) propor planos de desenvolvimento do HSM, tendo em vista a sua adequação às necessidades da Escola em termos de meios humanos e materiais (id., ibid., cláusula $2^{\mathrm{a}}$, 21 de Maio de 2007, p. 2).

Embora a Escola de Enfermagem e o Hospital se considerem articulados institucionalmente para efeitos de realização de estágios, o Protocolo de Articulação apresenta-se como um documento imprescindível para a planificação e formalização dos estágios. Ele constitui-se, neste sentido, como ponto de referência para os responsáveis mais directos da Escola e do Hospital (ou por um grupo de colaboradores com competência reconhecida para esta tarefa) construírem os programas/projectos sectoriais e respectivos documentos (plano anual de actividades, planificação disciplinar, protocolos de intervenção de cuidados, princípios orientadores da prática clínica, instrumentos de colheitas de dados, guias e regulamentos de estágio, instrumentos de avaliação, entre outros).

Ainda numa linha eficientista, o Protocolo de Articulação permitirá a aquisição ou troca de bens e o acesso aos diferentes meios, tais como: transferências de verbas, tratamento preferencial em acções de formação pós-graduada e frequência de cursos, acesso facultado às instalações e equipamentos e ainda à participação em acções culturais ou científicas.

O Regime de Articulação não é indiferente ao próprio modelo de supervisão de estágios, embora este não esteja explicitamente mencionado no documento. O modelo de supervisão mais congruente com um tipo de Articulação Eficiente (Imposta) corresponde ao Modelo de Supervisão como Inspecção ou como Produção, porque se integra num quadro construído e 
fixado em torno de objectivos oficiais das organizações (para as organizações), é atribuidor de significado normativo à acção organizacional, institui uma hierarquia formal e distribui atribuições e competências. Estamos perante o modelo que toma por referência a racionalidade (a priori) do ponto de vista da sua administração centralizada.

A articulação Escola de Enfermagem e Hospital num tipo de "Organização Acção", cujo pressuposto teórico é o Modelo de Sistema Social (Ellström, 1983), também nos remete para a possibilidade de uma Articulação de Interdependência e Colaboração - Integrativa/Adaptativa. Suportada por uma concepção organizacional de escola que prefere o consenso, a harmonia, a integração, a articulação, os valores partilhados e as relações informais, com a Configuração de Articulação de Interdependência e Colaboração - Integrativa/Adaptativa pretendemos equacionar a ideia de articulação que procura realçar a sua dimensão processual de proximidade com os actores das organizações, tendo em vista uma efectiva colaboração.

É neste cenário conceptual que nos parece estar desenhado o primeiro protocolo interinstitucional Escola de Enfermagem e Hospital. O primeiro Protocolo de Colaboração entre o HSM-B e a ESE-CG, que entrou em vigor em 1996/1997, parte do objectivo comum entre os serviços dependentes do Ministério da Saúde: "A saúde da Comunidade que servem". Neste documento estão explicitamente descritas as "competências organizacionais" de cada uma das organizações, o que deixa transparecer, de algum modo, a perspectiva da cultura organizacional da época, respeitante ao estágio e à própria formação dos alunos. O conteúdo do Protocolo de Colaboração enfatiza dimensões do Modelo de Sistema Social (Ellström, 1983), que compreende as actividades de integração, de interdependência e colaboração, como forma de garantir a socialização dos alunos estagiários nos "submundos institucionais especializados" (Berger \& Luckman, 1975), a adaptação ao ambiente e a estabilidade. Ele é francamente dirigido para a formação dos alunos em estágio. Isto significa que a Configuração de Articulação pode admitir a simultaneidade de uma sinergia com funções integrativas e adaptativas, como nos mostra o seguinte texto extraído do Protocolo de Colaboração:

(...) Ao HSM competia: 1.2 Permitir a colaboração do seu pessoal de enfermagem na aprendizagem prática dos alunos de acordo com as 
orientações ajustadas entre a Escola e a Direcção de Enfermagem. 1.3 Facilitar aos alunos a utilização do refeitório, a fim destes nele tomarem a refeição que inclua o turno em que efectuarem a prática clínica. $O$ aluno pagará a refeição ao preço previamente estipulado pelo Hospital e apresentar-se-á no refeitório devidamente fardado (...) (Protocolo de Colaboração entre o HSM e a ESECG, 1996).

Neste caso, a supervisão deve atender à clarificação dos valores, dos grandes objectivos, da visão da organização relativamente ao futuro e dos traços específicos que diferenciam cada uma das organizações (Escola de Enfermagem e Hospital). Subentende-se uma coerência do percurso formativo dos alunos, que engloba períodos de teoria na Escola e estágio no contexto clínico hospitalar. Os compromissos organizacionais passam pela realização da análise integrada de saberes complementares e de experiências vividas na formação inicial e na prática profissional, tendo em vista a parceria. Em suma, as sinergias do trabalho em parceria remetem para posições concertadas, através de estratégias de entre as quais se salientam os momentos de integração, os contratos de aprendizagem e de tutorias, cujo sentido é o da construção e desenvolvimento de projectos profissionais ou de formação. Dentro desta lógica, os processos de articulação são encarados mais como fenómenos espontâneos, acentuando o seu carácter adaptativo e muito menos a intencionalidade da acção organizacional. Valorizam-se especialmente processos dialécticos, dinâmicos, colaborativos, que se complementam.

\subsection{A articulação Escola de Enfermagem e Hospital num tipo de "Organização Política" - Entre as ideias, decisões e acções}

A nossa proposta de articulação Escola de Enfermagem e Hospital num tipo de "Organização Política" compreende os pressupostos teóricos do Modelo Político e do Modelo Anárquico (Ellström, 1983). Se no Modelo Político configuramos uma Articulação Conflitual - Estratégica, no Modelo Anárquico configuramos uma Articulação Débil - Simbólica. O posicionamento destes dois pressupostos num tipo de "Organização Política" justifica-se porque ambos exigem o reflexo de inconsistências, tais como: "dissolução, desintegração, isolamento e variedade nas estruturas, nos processos e nas ideologias". Tal como menciona Nils Brunsson (2006: 54): 
"Não é lutando por um único interesse que a 'política' ganha legitimidade e adquire recursos, mas antes pela sua associação a vários interesses e demonstrando a sua incorporação na sua própria existência. A organização justifica-se a si própria enquanto veículo para a reflexão em torno destes múltiplos interesses. A isto chama-se política pela justificação, mais do que uma política pela troca".

Neste quadro, as organizações Escola de Enfermagem e Hospital apresentam-se-nos com objectivos, estratégias e procedimentos que, mais do que racionais, estáveis ou consensuais, se manifestam de modo instável, incerto, divergente e conflitual. Isto significa que pode estar em causa a interacção entre vários grupos, com interesses especiais dentro das organizações. Este último facto é de extrema importância para o nosso estudo porque, independentemente da forma como se gerem os interesses dos diferentes grupos, interessa-nos, sobretudo, perceber como é que as organizações dão respostas aos "demasiados conflitos de interesse", ou seja, como é que obtêm legitimidade e adquirem recursos.

Pretendemos, portanto, utilizar os desenvolvimentos reflexivos ao nível micropolítico para caracterizar um tipo ideal de articulação que designámos por Articulação Conflitual - Estratégica, na medida em que as actividades inerentes à supervisão de estágios podem ser entendidas como espaços privilegiados para a manifestação da dinâmica conflitual. $O$ contexto da decisão é considerado como uma "arena de luta política", representado por grupos que conseguiram impor as suas posições. Os outros grupos, "minoritários", que não participaram em momentos cruciais do contexto da decisão, terão certamente dificuldades em aceitar, apoiar ou pôr em prática as decisões produzidas. Isto significa que a eficácia da articulação interorganizacional dependerá do confronto entre estruturas formais da organização (manifestadas pela existência de normas e hierarquias segundo as quais se pretende estruturar uma ordem estável) e estruturas informais (caracterizadas pela actualização das regras do jogo político). Este processo é analisado por Michel Crozier (1985), que o definiu como a "estratégia da incerteza", na qual o poder pode assumir formas discricionárias, quer tenha por origem a estrutura formal ou a informal.

O Protocolo de Articulação entre a Escola de Enfermagem e o Hospital, num contexto de supervisão de estágios, poderá assumir frequentemente uma negociação conflitual, de carácter sectorial, valorizando 
apenas uma dimensão parcelar do que é a Escola e do que é o Hospital. Mas também o percurso político poderá ser equacionado de uma outra forma e a concepção do Protocolo de Articulação ser alterada, possibilitando uma amplitude suficientemente difundida, de modo a permitir acolher interesses sujeitos a uma (re)interpretação de acordo com o sentido que os grupos acharem melhor seguir, para defenderem as suas posições. Assim, as faces desta configuração de articulação têm alguns traços dominantes: a complexidade, o prolongamento, o comprometimento, o dialéctico e o conflitual. Estes traços, traduzidos na supervisão de estágios, poderão dar origem a estratégias e processos de supervisão interactivos e de diferentes estilos, dando a possibilidade aos actores organizacionais, especialmente aos implicados na supervisão de estágios, de agirem perante o confronto de situações reais, de modo a desenvolverem a capacidade emancipatória.

Uma outra configuração de articulação Escola de Enfermagem e Hospital, que designamos por Articulação Débil - Simbólica, num tipo ideal de "Organização Política", é possível ser perspectivada. Neste caso, tentaremos configurá-la com base nos pressupostos teóricos do Modelo Anárquico.

Segundo o Modelo Anárquico apresentado por Per-Erik Ellström (1983), a ideia de um Protocolo de Articulação entre a Escola de Enfermagem e o Hospital, como instrumento orientador e vinculador das actividades de supervisão dos diversos intervenientes das duas organizações (ou pelo menos de alguns, como pretendia a Configuração de Articulação Conflitual Estratégica, relativamente aos grupos dominantes), deixa de fazer sentido. Aquilo que esta configuração nos poderá oferecer serão objectivos problemáticos, vagos, mal definidos, tecnologias e estratégias pouco claras, improvisadas e elaboradas com base numa participação fluida (Cohen et al., 1972) e que, por isso, são caracterizadoras de uma organização debilmente articulada em que os discursos se encontram pouco vinculados à realidade, a intenção desvinculada da acção, os objectivos, pouco precisos, desfasados dos resultados, e a planificação sem estratégias suficientemente definidas das suas consecuções na prática.

A partir desta perspectiva simbólica, muitos momentos que fazem parte da planificação racional não são mais do que cerimónias que toda a organização leva a cabo para manter a sua legitimidade, tanto em relação à imagem que se pretende dar a conhecer ao exterior, como em relação às 
próprias pessoas implicadas - que, ao planificarem, constroem uma fantasia partilhada que pretende ser eficaz. São variadas as situações de desenvolvimento da supervisão de estágios que poderíamos invocar para ilustrar a nossa análise, designadamente aquelas em que não existe uma conexão forte entre a intenção, a decisão e a acção e onde, de acordo com a análise de Brunsson (2006), as organizações manifestam a sua dupla face a Organização para a Acção e a Organização Política.

No caso do Protocolo de Articulação entre a Escola de Enfermagem e o Hospital, se pensarmos que as decisões e os decisores controlam as acções e os actores, acabamos por pensar na coerência que tem que existir entre o discurso, as decisões e as acções nas organizações. Desta forma, a legitimidade gozada pelas duas administrações pode ser projectada para as acções. Numa linha de orientação política, torna-se necessária a "reivindicação do mito do controlo", quando essas organizações são expostas ao olhar externo.

O Protocolo de Articulação entre a Escola de Enfermagem e o Hospital constituirá, assim, uma actividade simbólica, um ritual que, à semelhança de muitos outros, as organizações Escola de Enfermagem e Hospital incorporam na sua estrutura formal de modo a pacificar as expectativas sociopolíticas da sociedade em geral e da comunidade local em particular, legitimando, assim, a sua função enquanto instituição. Se, por um lado, é importante a aparição do documento escrito que implemente ou legitime o Protocolo de Articulação entre a Escola de Enfermagem e o Hospital, por outro, torna-se ainda mais necessário que se desencadeiem acções de grande visibilidade, quer da Escola, quer do Hospital, fazendo acreditar os actores que as duas organizações dispõem de uma equipa especialmente dedicada à elaboração de projectos comuns indispensáveis ao sucesso organizacional. Estamos perante um cenário de Hipocrisia. A Hipocrisia surge como necessária às duas organizações, dando resposta ao problema das normas inconsistentes com que se depara a organização (Brunsson, 2006: 204):

"A hipocrisia significa que as ideias e a acção não se apoiam directamente. Por outro lado, podemos afirmar que a acção está a ser protegida e que a administração satisfaz, através do discurso, as exigências que a própria acção não consegue satisfazer". 
A desarticulação entre estruturas organizacionais da Escola e do Hospital e a supervisão de estágios não significa, no entanto, que possa pôr em causa os processos de supervisão, no contexto hospitalar, de índole pessoalista, desenvolvimentista, onde a dimensão política e emancipatória da formação está presente. $\mathrm{O}$ facto de os elos das estruturas organizacionais se apresentarem frouxos poderá, em certa medida, permitir e facilitar os processos interactivos de supervisão entre alunos estagiários e profissionais, assim como permitir conhecer e intervir nas organizações. Daí que admitamos a possibilidade de ocorrer uma Articulação Débil entre as duas organizações (Escola de Enfermagem e Hospital) e, simultaneamente, outros modos de realizar a supervisão no contexto de estágio. Referimo-nos a estratégias de supervisão superadoras de dualismos, na gestão do ensino (Escola de Enfermagem) e do estágio, na instituição onde ele ocorre (Hospital), em que estas duas organizações aparecem como um espaço onde convergem as distintas dimensões de outras configurações analisadas. A este propósito, citamos uma nota de reflexão de uma comunicação intitulada "aprendizagens e quotidianos profissionais", proferida por Rui Canário (2007: 185)6 ${ }^{6}$, em que se reforça a ideia de que o desenvolvimento das práticas clínicas por parte das escolas de formação inicial deve ser entendido, por estas, como uma modalidade de formação:

A concretização desta estratégia significaria estabelecer, enfim, uma sinergia profunda entre as escolas onde se privilegia uma via simbólica de construção do conhecimento e um contexto de trabalho em que se privilegia uma via de construção do conhecimento, baseada na experiência. Porque são indissociáveis, estas duas dimensões, embora em diferentes graus, estarão sempre presentes num e noutro destes dois lugares.

\section{Configurações da articulação Escola de Enfermagem e Hospital, em contexto de supervisão de estágio, no Plano da Acção Organizacional/Sistema de Acção}

As quatro Configurações de Articulação apresentadas ("tipos ideais") Articulação Eficiente - Imposta; Articulação de Interdependência e Colaboração - Integrativa/Adaptativa; Articulação Conflitual - Estratégica; Articulação Débil - Simbólica - estabelecem o enquadramento conceptual em que nos vamos apoiar para classificar outras configurações que possam estar presentes no "Plano da Acção" ou "Sistema da Acção", no contexto da 
supervisão de estágios. Esses "tipos ideais" são construções abstractas, que ajudam a sistematizar e compreender melhor a realidade, embora não se encontrem reproduzidos de forma integral nos contextos reais.

Assim, as quatro Configurações propostas para a caracterização da articulação entre a Escola de Enfermagem e o Hospital podem, em determinados momentos, estar representadas, diferentemente, por diversos actores intervenientes no estágio de Medicina (alunos estagiários, enfermeiros, supervisora), mas há evidências de que, neste contexto de supervisão, a Configuração da Articulação Conflitual - Estratégica surge, globalmente, marginal face às questões organizacionais por nós analisadas.

A análise da informação recolhida a partir dos actores concretiza, em nosso entender, uma Configuração de Articulação Débil - Simbólica entre a Escola de Enfermagem e o Hospital. No entanto, esta conclusão não é fácil de obter, porque a natureza do discurso dos actores é complexa, estando sujeita a uma interpretação de acordo com "o olhar do outro", ou o olhar do investigador, e, ainda, de acordo com o olhar dos outros actores. Neste último caso "o olhar" está dependente do estatuto do actor (aluno estagiário ou profissional).

Iniciamos então a nossa análise dos discursos dos alunos estagiários. Relativamente à articulação desejável para a supervisão do estágio, balanceia entre Configurações de Articulação Eficiente - Imposta e Articulação de Interdependência e Colaboração - Integrativa/Adaptativa. Vejamos alguns depoimentos, nos quais é possível identificar as expectativas destes actores em relação às áreas em que a intervenção dos responsáveis pelos estágios poderia ser incrementada. Relativamente à primeira, Articulação Eficiente Imposta, as falas dos alunos estagiários enfatizam uma concepção de articulação interorganizacional entendida como uma tecnologia racional para a tomada de decisões, concretizada num acompanhamento sistematizado, coerente com os objectivos antecipadamente identificados e centrada nos resultados de aprendizagens:

"Acompanhamento dos estagiários desde o início do estágio e uma preocupação maior com os resultados de aprendizagem. Porque penso que acima de tudo o ensino clínico deve ser considerado como uma oportunidade de aprendizagem e considero fundamental o acompanhamento permanente dos estagiários" (Est.1). 
Já as falas seguintes nos remetem essencialmente para uma concepção de Articulação de Interdependência e Colaboração Integrativa/Adaptativa. Conseguir uma articulação em "sintonia" e incentivar a "parceria" são alguns objectivos, por isso estes actores reforçam a ideia de uniformização das políticas de supervisão para as duas organizações. A supervisão desejável deveria investir em actividades ou programas em que os alunos estagiários pudessem participar, para se sentirem mais próximos da organização hospitalar e das suas práticas:

"Incentivar actividades em parceria. Considero que a relação Escola e Hospital podia ser mais estreita e não se cingir apenas ao momento de estágio, pelo menos no que diz respeito aos alunos. Poderiam ser desenvolvidas ao longo do ano actividades em parceria com o Hospital em que os alunos pudessem participar para se sentirem mais próximos da Instituição. Seria uma forma de desenvolverem outras competências novas" (Est.3).

As incongruências de articulação reflectem-se nas estratégias de supervisão e são relatadas pelo grupo de alunos em estágio no serviço de Medicina. São alguns exemplos: sensibilidades diferentes aos processos de integração e formas de acompanhamento; divergências nas formas de orientação; tempo de permanência na orientação.

Essas falas são também reveladoras de incongruências entre uma e outra organização e dentro da mesma organização: práticas de cuidados distintas; orientações conflituantes; condicionantes de vária ordem (espaço, tempo, ignorância); irregularidades (falhas de comunicação). Estas desconexões podem ser geradoras de "infidelidades normativas", ou constituírem-se, em si, de "infidelidades normativas" (Lima, 1998).

Os documentos oficiosos relativos ao estágio ocorrem ao nível de grupos restritos, o que, à partida, inibe a participação dos actores nos diversos processos de supervisão de estágios. Há uma maioria de profissionais de Enfermagem que considera que o Protocolo de Articulação deveria incluir outros actores e um trabalho conjunto: a "formação de tutores e auxiliares de ensino", a "criação de novos cursos na Escola com a vertente específica supervisão de estágios", o "incentivo a actividades em parceria", a "organização de acções de formação em conjunto", a "definição em conjunto de políticas de supervisão". 
Perante a análise que fizemos a outros discursos, foram-nos surgindo relatos contraditórios com a lógica da participação e da intervenção dos actores, oferecendo-nos indicadores próximos do pragmatismo e do cumprimento dos requisitos de eficácia que caracterizam estas perspectivas.

A Articulação Débil - Simbólica entre a Escola e o Hospital aparecenos caracterizada de diferentes modos pelos actores intervenientes no contexto da supervisão de estágios. No entanto, há algumas ideias que tendem a prevalecer em todos os depoimentos. Os acontecimentos interorganizacionais surgem relativamente desconectados, embora muitas vezes publicitados como sendo pensados em conjunto. $O$ investimento participativo dos gestores dessas estruturas é débil e eles podem criar momentos formais sem grande intenção de que os seus efeitos interfiram na acção real. A articulação é ainda marcada por um certo grau de ambiguidade, o que contribui para o desenvolvimento de percepções e lógicas divergentes e para as desconexões entre ideias e acções, intenções e concretizações.

Alguns dos relatos de enfermeiros e da supervisora permitiram-nos identificar Configurações de Articulação Escola de Enfermagem e Hospital que, na nossa opinião, não passam de derivantes da Articulação Débil. Há certos aspectos encontrados nos discursos dos actores que nos permitem identificar alguns cambiantes desta articulação - Articulação "assim está bem"; Articulação "unidireccional'; Articulação "passa ao lado"; Articulação "utilitarista" ; Articulação "tentativa".

A Articulação "assim está bem" trata-se de uma articulação cómoda, sem qualquer responsabilidade por parte da organização que recebe os alunos estagiários, neste caso o Hospital. Os actores da organização hospitalar estão pouco implicados ou nada envolvidos em todo o processo de supervisão de estágio:

Considero que assim está bem, há uma integração gradual da prática de cuidados. Penso que se a Escola não estivesse presente a comunicação entre instituições Escola - Hospital estaria mais dificultada, penso que assim como está, está bem. (...) A minha participação na preparação dos ensinos clínicos não a considero necessária, porque é função da entidade de ensino (Enf.1).

A Articulação "unidireccional" é uma articulação dos responsáveis pela gestão das organizações. Caracteriza-se por possuir um protocolo de articulação unidireccional, não sujeita a um sistema participativo dos vários 
intervenientes do estágio. Esta perspectiva, exclusiva dos órgãos de gestão, quer da Escola, quer do Hospital, concretiza-se em momentos cruciais: o da formalização dos pedidos de estágios e o da reunião de preparação e avaliação dos estágios:

O protocolo de colaboração entre a Escola e os serviços é unidireccional, em que se faz essencialmente através da formalização dos pedidos dos campos de estágio. A preparação dos estágios realiza-se entre professores e enfermeiros chefes, sendo que os estudantes são socializados de uma forma passiva (Enf.2).

A Articulação "passa ao lado" é traduzida por um desconhecimento total, por parte dos actores, acerca do protocolo de articulação Escola e Hospital. Relativamente à supervisão de estágios, apenas existem comentários vagos, pouco precisos, sem objectivos e estratégias suficientemente definidas e operacionalizáveis, capazes de vincular as práticas:

Como profissionais, a articulação Escola e Hospital passa-nos um pouco ao lado. Sei que os pedidos de estágio são dirigidos ao topo, ao nível da gestão. O enfermeiro chefe pronuncia-se, mas nós não sabemos de mais nada (Enf.3).

A Articulação "Utilitarista" implica que uma organização se sirva da outra e o estágio adquire o estatuto de articulador utilitário entre as duas organizações - Escola de Enfermagem e Hospital. Há uma colaboração mínima interorganizacional, pouco compensatória, a nível pessoal e profissional, para os actores intervenientes do estágio, que se limitam a seguir e a utilizar os instrumentos de avaliação que a Escola recomenda:

Considero que este Hospital tem um contacto mais próximo com a Escola, precisamente na área dos ensinos clínicos, que tem um carácter essencialmente utilitário (Enf.4).

O relato da supervisora permite-nos identificar uma outra Configuração de Articulação entre a Escola de Enfermagem e o Hospital: a Articulação "tentativa". Em determinados momentos, há um certo voluntarismo, por parte de alguns actores, em colaborarem, na tentativa de ambas as partes (Escola de Enfermagem e Hospital) se articularem. Essa coordenação de esforços diz apenas respeito à dimensão pedagógica da supervisão de estágios:

Há uma tentativa de ambas as partes em se articularem, quando há uma coordenação de esforços em reflectir sobre a teoria e a prática. O projecto entre Escola e Hospital deverá ser facilitador das aprendizagens dos alunos (Sup.). 
As falas destes actores anunciam representações da Escola de Enfermagem e Hospital como entidades independentes, com fronteiras descontinuamente estabelecidas, procurando, simultaneamente, a cooperação sistemática, o consenso e a supressão de todo o tipo de conflito, subordinada à obsessão da eficácia e da eficiência. Ao interpretarmos os contextos organizacionais, a visão comum que suporíamos encontrar era a de que o pensamento e as ideias controlassem as acções. Mas nem sempre foi isto que aconteceu, ou seja: tendo em conta a nossa interpretação das acções implementadas pelas duas organizações, verificámos que algumas acções controlavam as ideias. As falas, nestes casos, tomavam o formato de explicações que tinham "como finalidade última a legitimação". Tal como refere Brunsson (2006: 203):

"Quando se pretende que as ideias controlem a acção, é necessário que estas sejam reduzidas ao nível mais concreto da acção; porém, quando se pretende que elas expliquem a acção, é provável que se possam distanciar do concreto e, nesse sentido, se tornem abstractas e mais inconsistentes".

Noutras situações, os discursos apareciam adaptados a algumas normas, enquanto as acções adaptadas a outras. No nosso entender, este quadro permite que a hipocrisia organizacional se manifeste como dimensão necessária e benéfica na perspectiva do desenvolvimento das organizações. A manutenção de certas práticas, convenientes (ou mais cómodas) a cada uma das organizações, "pode revelar-se mais importante do que a acção organizada e do que a eficácia organizacional" (Lima, 2006: 7). Referimo-nos concretamente à falta de participação da Escola na selecção de auxiliares de ensino e sua formação e à falta de participação do Hospital nas actividades de âmbito pedagógico (incluindo as estratégias do planeamento, programação, orientação e avaliação dos ensinos clínicos e estágios e a construção de documentos relativos à supervisão de estágios).

Porém, para todos os efeitos formais, estas duas organizações têm um Protocolo de Articulação Institucional entre a Escola e o Hospital (2007) à disposição de quem o solicitar, que cumpre os requisitos formais, ainda que, em termos de conteúdo, não se trate propriamente de um Protocolo que nos indicie um projecto comum, mas de uma "listagem de compromissos", que cada organização deverá cumprir. 
O Protocolo de Articulação entre a Escola de Enfermagem e o Hospital, aparece-nos, assim, representado como um artefacto que contribui para engrandecer o conjunto de preceitos estruturais destas duas organizações, cumprindo dois objectivos: por um lado, "dar resposta às exigências e expectativas sociais, políticas, administrativas e legais" (Costa, 1997), e, por outro, legitimar, quer a razão de ser deste cumprimento legal, quer a "imagem de competência e de qualidade" (Costa, 1997) das duas organizações.

Neste exercício, concluímos que o estágio foi revelador de articulações e de desarticulações, permitindo-nos traçar um mapa das suas configurações a partir de vários intervenientes: alunos estagiários, enfermeiros, supervisor, investigadora.

O Protocolo de Articulação entre a Escola de Enfermagem e o Hospital deu conta da parte mais visível do discurso exarado em diploma legal relativo à criação de condições para o desenvolvimento de uma parceria efectiva entre os Ministérios da Educação e da Saúde, quando, em 2001, o DecretoLei no99/2001, de 28 de Março, assim proclamava nos seus Art. ${ }^{\circ}{ }^{\circ}$, alínea f), e Art. $^{\circ} 10$, alínea c):

Art. $^{\circ} 9^{\circ}$ f) A definição de princípios orientadores da cooperação e coresponsabilização entre os estabelecimentos de ensino e os serviços prestadores de cuidados de saúde, incluindo um sistema de acreditação periódica destes e dos seus recursos humanos, tendo em vista uma formação de qualidade.

Art. $^{\circ} 10^{\circ} \mathrm{C}$ ) Assegurar, através dos serviços prestadores de cuidados de saúde do Serviço Nacional de Saúde, as condições de aprendizagem clínica para os cursos e garantir os respectivos padrões de qualidade.

Depois de termos descrito e analisado alguns aspectos particulares caracterizadores das articulações presentes entre a Escola e o Hospital, a partir de uma diversidade de dados recolhidos, interessa neste momento sublinhar, em jeito de síntese, as lógicas e os requisitos organizacionais que se conseguem traduzir das configurações desenhadas.

Comecemos pela organização Escola de Enfermagem, que, neste estudo, parece inclinar-se para uma Configuração de Articulação interorganizacional Débil - Simbólica. A aproximação ao Sistema Debilmente 
Articulado de Karl Weick dá-se quase sempre quando entre estruturas, órgãos e acontecimentos não existe uma união forte, uma coordenação eficiente e racional, mas antes uma conexão frouxa, ou mesmo uma desarticulação relativa, entre os diferentes elementos. Esses elementos, no caso da articulação interorganizacional Escola de Enfermagem e Hospital, embora aparentemente unidos, porque concretizam um Protocolo de Articulação, mantêm-se ligeiramente afastados para preservarem uma identidade própria.

A supervisão de estágios é exemplificativa da posição da Escola, que parece rejeitar a ideia de que seja desejável descobrir laços entre um sistema racionalizado e o incremento da eficácia. No entanto, a um determinado nível, a Escola evidencia a possibilidade de uma interdependência "directa" entre as dimensões estrutural, normativa e técnica, presentes quer no seu interior, quer na sua presença dentro da organização hospitalar.

De acordo com o nosso quadro teórico-conceptual, para que fosse possível uma articulação no molde da eficácia e da eficiência, além de estarem definidas as regras, ou um acordo sobre o que seriam as regras, o sistema de retroinformação deveria estar orientado para melhorar a obediência. A presença de um Modelo de Supervisão como Inspecção ou como Produção cumpriria estes requisitos, mas o nosso estudo não comprovou tal facto.

A Articulação Interorganizacional Débil nasceu de um processo de democratização que tornaria a Escola de Enfermagem mais flexível e aberta ao exterior. O percurso da construção da Articulação Débil ou de reconversão de um tipo de articulação forte, eficiente, imposto não foi feito com passos largos, mas mitigados, capaz de ir mantendo a sua estabilidade na relação interorganizacional Escola-Hospital. Aliás, ao longo do percurso investigativo pudemos constatar a manutenção de relações cordiais entre a Escola e o Hospital, principalmente através dos órgãos de gestão das duas organizações.

Fruto de uma integração recente numa Universidade, a direcção da Escola tem procurado aproximá-la de uma "comunidade académica" e assumi-la como organização capaz de enfrentar, analisar e resolver os problemas próprios de uma sociedade. Se, por um lado, a abertura de espaços para a expressão dos valores académicos fundados na autonomia, na responsabilidade, na filiação científica, na colegialidade e cooperação 
interorganizacional trouxe um desafio para a Escola, por outro lado, a sua contribuição para a promoção da sua sustentabilidade institucional e da sua competitividade no espaço global não deixa de constituir motivo de preocupação. Este facto suscita o questionamento acerca das condições de funcionamento da Escola de Enfermagem, enquadrada dentro de uma organização que é pública e que tem estratégias e objectivos distintos de outras organizações concorrentes, que ultimamente têm proliferado no campo da Enfermagem.

No que diz respeito à organização hospitalar do nosso estudo, esta pareceu inclinar-se para uma Configuração de Articulação interorganizacional Eficiente - Imposta. Este tipo de configuração é representado em conformidade com o aparelho burocrático presente na organização hospitalar, através do qual constitui regras e procedimentos protocolados, estáveis e uniformes, cujo efeito é reforçado por mecanismos de coacção e controlo, para que se consiga garantir a eficiência organizacional. A supervisão de estágios denunciou como desejável uma visão burocrática-racional da articulação, pressupondo que a relação interorganizacional funcionasse segundo objectivos claros e consensuais, em torno dos quais se movem os actores, e em conformidade com as actividades de carácter obrigatório, organizadas num plano racional único, planeadas para atender aos objectivos oficiais da organização (cf. Goffman, 1974: 17-18).

O ordenamento burocrático-racional, no estudo, surge com alguma frequência muito associado à eficiência e à produtividade organizacional, pela importância de se responder às necessidades de saúde dentro de uma linha produtivista e eficientista, como hoje é apregoado na generalidade dos discursos oficiais. Neste sentido, o dispositivo burocrático representa os espaços e os tempos dentro dos quais os actores organizacionais interactuam e nos quais a dinâmica organizacional se processa, acautelando desvios excessivos que podem colocar em risco a unidade organizacional mínima que assegura a manutenção e a continuidade da organização. É compreensível que assim seja, numa organização complexa como é o Hospital, para que esteja garantido o suporte básico das operações a nível da administração e gestão.

Embora cada Configuração de Articulação Interorganizacional Escola de Enfermagem e Hospital constitua um pretexto para apreciar as diferentes 
variações que cada uma delas pode adquirir, ajudando a compreender alguns aspectos da dinâmica da supervisão de estágios (ligados quer à regulação burocrática, de sistema social, política ou anárquica), é essencialmente com elementos de dupla natureza que nos aparece influenciada esta articulação: racional-burocrática, impondo padrões de conformidade e hierarquização da autoridade; e anárquica, sublinhando a importância do simbolismo e da ambiguidade organizacional. A acção desses elementos pode exercer-se isoladamente ou em conjunto e, neste caso, podem ocorrer em simultâneo ou simplesmente excluírem-se. A dinâmica de articulação interorganizacional Escola e Hospital pode ser analisada a partir da compreensão das articulações e desarticulações que se produzem entre a dimensão racionalburocrática e a anárquica enquanto elementos que estruturam as relações, interacções e processos organizacionais, cujas características derivam dos efeitos verificados dessas articulações ou desarticulações.

O presente estudo resulta na congregação de acções e lógicas afectas tanto à estrutura burocrática como à estrutura anárquica e outras menos relevantes, actuando essencialmente em dois sentidos: estabilidade convergente, quando ambas as estruturas justificam as razões para a acção e a convergência dos pensamentos, com vista à concretização de objectivos comuns; ou flexibilidade divergente, quando se trata de dar cumprimento a iniciativas que apenas servem uma das organizações. Neste último sentido, cada uma das estruturas tenta mobilizar meios e desenvolver estratégias para que as decisões tomadas estejam o mais de acordo possível com as pretensões dos actores.

É no contexto de supervisão de estágios que são reveladas algumas dimensões das diferentes articulações, através dos seus elementos característicos: a uniformidade e a divergência. Embora neste estudo de caso a natureza política das organizações Escola e Hospital não apareça explicitada nos discursos dos actores intervenientes na supervisão de estágios, não foi, descurada esta dimensão, uma vez que estavam em jogo relações de "cooperação dos actores ao redor dos 'problemas' e das suas 'soluções"' (Friedberg, 1995: 170).

Para concluir, parece-nos claro que, se tivéssemos encaminhado a nossa investigação sobre a articulação interorganizacional de acordo com uma perspectiva situada exclusivamente na análise das respectivas 
estruturações formais (com base apenas nos documentos institucionalmente considerados), ficaríamos certamente a conhecer a face mais visível, captável pela lógica interpretativa mono-racional; porém, desconheceríamos as diversas lógicas presentes nas representações dos actores, que necessariamente intervêm na supervisão de estágios, os processos sociais em jogo e as dinâmicas interorganizacionais. O exercício de articulação entre a Escola de Enfermagem e o Hospital, a partir do ponto de intersecção - a supervisão de estágios -, além de contribuir para uma interpretação teórica das especificidades de cada uma das organizações, ora científicopedagógicas, ora organizacionais, mostrou-nos as diferentes Configurações de Articulação, de intensidade e frequência por vezes inconstantes e variáveis, que mais não significam do que as condições multirreferenciadas de acção interorganizacional Escola de Enfermagem e Hospital.

\section{Notas}

1 Ver o trabalho de Lise Demailly e Oliver Dembinski: "La réorganisation managériale à l'école et à l'hôpital", 2002.

2 Segundo Amitai Etzioni, o fundamento da autoridade do especialista é o conhecimento e a relação entre a autoridade administrativa e a especializada, muito influenciada pela proporção e tipo de conhecimento do especialista. Esta relação é válida "nas organizações em que a autoridade especializada se fundamenta numa longa formação (5 ou mais), quando abrangem questões de vida e morte ou comunicação privilegiada, e quando cria ou aplica o conhecimento, em vez de apenas transmiti-lo". No caso da enfermagem, o autor designa a profissão de semiespecializada menos típica, relativamente à dos médicos, que é especializada (Etzioni, 1984: 119).

3 A comparação da escola com o sector privado, no nosso caso, só terá interesse a partir de determinado período histórico, quando uma maioria das escolas se oficializou. Note-se que o ensino de Enfermagem em Portugal começou nos últimos anos do século XIX e partiu das iniciativas das administrações dos Hospitais da Universidade de Coimbra, Hospital Real de São José, Hospital Geral de Santo António da Santa Casa da Misericórdia do Porto (Decreto-Lei n 36219, de 10 de Abril de 1947).

4 A prestação de serviços é apresentada, na expressão "organização de serviços", de Peter M. Blau e Richard W. Scott, da seguinte forma: "Uma organização de serviços é definida como uma organização cujo principal beneficiário é a parte do público que tem com ela contacto directo, com quem e para quem seus membros trabalham - em resumo, uma organização cuja função básica é servir os seus clientes" (Blau \& Scott, 1977: 66-67). 
5 Ver o artigo de Licínio Lima: "Modernização, racionalização e optimização. Perspectivas neo-taylorianas na organização e administração da Educação", 1994.

6 II Ciclo de Colóquios - Identidades, aprendizagens e quotidianos profissionais, que decorreu no dia 24 de Novembro de 2005, na ESECGL.

\section{Referências}

Berger, P., \& Luckman, T. (1975). The social construction of reality. A treatise in the Sociology of Knowledge. Middlesex: Penguin Books Ltd.

Blau, P., \& Scott, R. (1977). Organizações formais. São Paulo: Atlas.

Brunsson, N. (2006). A organização da hipocrisia - Os grupos em acção: dialogar, decidir e agir. Porto: Asa.

Canário, R. (2007). Aprendizagens e quotidianos profissionais. In A. Rodrigues et al., Processos de formação na e para a prática de cuidados (pp. 175-185). Lisboa: Lusociência.

Cohen, M., March, J., \& Olsen, J. (1972). A garbage can model of organization choice. Administrative Science Quarterly, $\mathrm{n}^{\circ} 17,1-25$.

Costa, J. (1997). O projecto educativo da escola e as políticas educativas locais: Discursos e práticas. Aveiro: Universidade de Aveiro.

Crozier, M. (1985). Le phénomène bureaucratique. Paris: Éditions du Seuil.

Demailly, L., \& Dembinski, O. (2002). La réorganisation managériale à l'école et à l'hôpital. Éducation et Sociétés, $\mathrm{n}^{\circ}$ 6, 43-64.

Ellström, P.-E. (1983). Four faces of educational organizations. Higher Education, ${ }^{\circ} 12$, 231-241.

Etzioni, A. (1984). Organizações modernas. São Paulo: Livraria Pioneira.

Goffman, E. (1974). Manicómios, prisões e conventos. São Paulo: Perspectiva.

Lima, L. (1994). Modernização, racionalização e optimização. Perspectivas neotaylorianas na organização e administração da Educação. Cadernos de Ciências Sociais, $\mathrm{n}^{\circ}$ 14, 119-139.

Lima, L. (1998). A escola como organização e a participação na organização escolar. Um estudo da escola secundária em Portugal (1974-1998). Braga: Instituto de Educação da Universidade do Minho.

Lima, L. (2003). A escola como organização educativa. Uma abordagem sociológica. São Paulo: Cortez Editora.

Lima, L. (2006). Prefácio à edição portuguesa. In N. Brunsson, A organização da hipocrisia - Os grupos em acção: dialogar, decidir e agir. Porto: Asa.

Messine, P. (1991). Os saturnianos. Quando os patrões reinventam a sociedade. Lisboa: Edições Sagres - Promontório.

Tyler, W. (1991). Organización escolar: Una perspectiva sociológica. Madrid: Morata.

Weick, K. (1976). Educational organizations as loosely coupled. Administrative Science Quarterly, 21(1), 1-19. 


\title{
SUPERVISION OF INTERNSHIPS AS AN ANALYSIS OF INTERORGANIZATIONAL ARTICULATION BETWEEN SCHOOL OF NURSING AND HOSPITAL
}

\begin{abstract}
This study, which reflects on the supervision of internships, is not a new issue in the context of nursing. However, the issue investigated as organizational subject appears in the portuguese context as a novelty. The thesis focuses on the guidelines and practices of supervision placements in Nursing as an analyzer of the interorganizational articulation Nursing School and Hospital phenomena. The course of this investigation was the interlace between some changes in oversight of internships and some social and political changes of the organizations under study - School of Nursing and Hospital - by setting up relations between both sociologically relevant. The heuristic value of this route led to (re)construct a theoretical model for the analysis of the interorganizational articulation Nursing School and Hospital, where two analytical approaches for their understanding were elected. Here, it will be presented theoretical and methodological framework of this case study, which allowed us to make the reading of the discourses and practices in the context of probation supervision, the Plan of Action/Action System.
\end{abstract}

Keywords

Supervision of placements in Nursing; Articulation School of Nursing and Hospital; Settings of articulation

\section{SUPERVISION DES STAGES COMME ANALYSEUR D'ARTICULATION INTER- ORGANISATIONNELLE ÉCOLE D'INFIRMIÈRES ET HÔPITAL}

\section{Résumé}

Cette étude, qui aborde la supervision des stages, ne constitue pas une nouvelle question dans le contour de l'école des Infirmières. Toutefois, la question comme objet d'enquête organisationnelle apparaît dans le contexte 
portugais comme une nouveauté. La thèse se penche sur les orientations et les pratiques de supervision de stage en École d'Infirmière, comme analyseur de phénomènes d'articulation interorganisationnelle École d'Infirmières et Hôpital. Le parcours de cette enquête a été celui d'une alliance entre quelques changements dans la supervision des stages ayant quelques modifications sociales et politiques des organisations étudiées - École d'Infirmières et Hôpital - , établissant ainsi des relations sociologiquement pertinentes entre les deux parties. La valeur heuristique de ce trajet a permis la reconstruction d'un modèle théorique d'études sur l'articulation interorganisationnelle École d'Infirmières et Hôpital, permettant ainsi deux options d'analyse pour sa compréhension. Ici, il sera présenté l'essai théorique et méthodologique de cette étude de cas, qui nous a permis de faire la lecture du discours et des pratiques dans le cadre de la surveillance de la probation, le Plan d'Action/Système d'Action.

Mots-clé

Supervision de stages; Articulation École d’Infirmiéres et Hôpital; Paramètres d'articulation

Recebido em Setembro, 2010 Aceite para publicação em Janeiro, 2011 